\title{
Antioxidant Activities and Tyrosinase Inhibitory Effects of Different Extracts from Pleurotus ostreatus Fruiting Bodies
}

\author{
Nuhu Alam', Ki Nam Yoon', Kyung Rim Lee', Pyung Gyun Shin'², Jong Chun Cheong'2, Young Bok Yoo', \\ Mi Ja Shim", Min Woong Lee ${ }^{4}$ U Youn Lee ${ }^{1}$ and Tae Soo Lee ${ }^{1 *}$ \\ ${ }^{\prime}$ Division of Life Sciences, University of Incheon, Incheon 406-840, Korea \\ ${ }^{2}$ Mushroom Division, National Institute of Horticultural \& Herbal Science, RDA, Suwon 441-707, Korea \\ ${ }^{3}$ Department of Life Science, University of Seoul, Seoul 130-743, Korea \\ ${ }^{4}$ Department of Biology, Dongguk University, Seoul 100-715, Korea
}

(Received October 13, 2010. Accepted October 26, 2010)

\begin{abstract}
We evaluated the antioxidant activity and tyrosinase inhibitory effects of Pleurotus ostreatus fruiting bodies extracted with acetone, methanol, and hot water. The antioxidant activities were tested against $\beta$-carotene-linoleic acid, reducing power, 1,1diphenyl-2-picrylhydrazyl free radical scavenging activity, and ferrous chelating ability. Furthermore, phenolic acid and flavonoid contents were also analyzed. The methanol extract showed the strongest $\beta$-carotene-linoleic acid inhibition as compared to the other exracts. The acetone extract $(8 \mathrm{mg} / \mathrm{mL})$ showed a significantly high reducing power of 1.54 than the other extracts. The acetone extract was more effective than other extracts for scavenging on 1,1-diphenyl-2-picrylhydrazyl radicals. The strongest chelating effect $(85.66 \%)$ was obtained from the acetone extract at $1.0 \mathrm{mg} / \mathrm{mL}$. The antioxidant activities of the extracts from the $P$. ostreatus fruiting bodies increased with increasing concentration. A high performance liquid chromatography analysis detected seven phenolic compounds, including gallic acid, protocatechuic acid, chlorogenic acid, naringenin, hesperetin, formononetin, and biochanin- $\mathrm{A}$ in an acetonitrile and $0.1 \mathrm{~N}$ hydrochloric acid $(5: 1)$ solvent extract. The total phenolic compound concentration was $188 \mu \mathrm{g} / \mathrm{g}$. Tyrosinase inhibition of the acetone, methanol, and hot water $P$. ostreatus extracts increased with increasing concentration. The results revealed that the methanol extract had good tyrosinase inhibitory ability, whereas the acetone and hot water extracts showed moderate activity at the concentrations tested. The results suggested that $\boldsymbol{P}$. ostreatus may have potential as a natural antioxidant.
\end{abstract}

KEYWORDS : Antioxidant, Phenolic compounds, Pleurotus ostreatus, Tyrosinase inhibition

Pleurotus ostreatus, commonly known as oyster mushroom, is an important edible fungus in Korea. It grows in a wide range of temperatures, utilizing various lignocelluloses, and is becoming more popular throughout the world [1]. P. ostreatus is a good source of dietary fiber and other valuable nutrients [2]. This mushroom contains a number of biologically active compounds with various therapeutic activities, including the ability to modulate the immune system, decrease blood lipid concentrations, prevent high blood pressure and atherosclerosis, as well as hypoglycemic and antithrombotic activities [3].

Oxidative damage caused by free radicals may be related to aging and diseases, such as atherosclerosis, diabetes, cancer, and cirrhosis [4]. Although almost all organisms possess antioxidant defense and repair systems that have evolved to protect them against oxidative damage, these systems are insufficient to entirely prevent damage [5]. However, antioxidant supplements or foods containing antioxidants may be useful to help the human body reduce oxidative damage. Mushrooms produce a variety

\footnotetext{
$\overline{\text { *Corresponding author }}<$ E-mail : tslee@incheon.ac.kr>
}

of secondary metabolites, including phenolic compounds, polyketides, terpenes, and steroids [6]. Recently, mushrooms were considered a good source of protein and phenolic antioxidants, such as variegatic acid and gallic acid [7].

Tyrosinase, also called polyphenol oxidase [8], is a copper-containing mono-oxygenase present in a diverse range of organisms and is responsible for melanization in animals and enzymatic browning of fruit. This enzyme catalyzes two distinct reactions involving molecular oxygen: the hydroxylation of monophenols to $o$-diphenols and the oxidation of $o$-diphenols to $o$-quinones [9]. The nutritional value and taste components of $P$. ostreatus have been thoroughly studied. Mushroom research has focused on nutritional and therapeutic effects, and little information is available on the antioxidant properties of mushrooms. Therefore, our objective was to evaluate the antioxidant activities of $P$. ostreatus, including $\beta$-carotenelinoleic acid, reducing power, scavenging effects on radicals, and chelating effects on ferrous ions. The potential phenolic and flavonoid compound contents and tyrosinase inhibition properties of $P$. ostreatus were also analyzed. 


\section{Materials and Methods}

Chemicals and reagents. $\beta$-carotene, linoleic acid, chloroform, polyoxyethylene sorbitan monopalmitate (Tween40), butylated hydroxytoluene (BHT), $\alpha$-tocopherol (TOC), 1,1-diphenyl-2-picrylhydrazyl (DPPH), L-ascorbic acid, potassium ferricyanide, trichloroacetic acid, ferrous chloride, ferric chloride, ferrozine, Folin-Ciocalteu reagent, gallic acid, methanol, 3,4-dihydroxy-L-phenylalanine (L-DOPA), mushroom tyrosinase, and dimethyl sulfoxide (DMSO) were purchased from Sigma-Aldrich (St. Louis, MO, USA). All chemicals and solvents used were high performance liquid chromatography (HPLC) or analytical grade.

Mushroom and extraction. Fresh, mature fruiting bodies of $P$. ostreatus (cultivar Chun Chu 2) were obtained from Hanultari mushroom farm, Korea. A pure culture was deposited in the Culture Collection DNA Bank of Mushroom (CCDBM), Division of Life Sciences, University of Incheon, Korea and acquired accession number, IUM-4143. Fresh fruiting bodies were dried with hot air at $40^{\circ} \mathrm{C}$ for $48 \mathrm{hr}$ and finely pulverized. Five grams of powdered samples were extracted with $100 \mathrm{~mL}$ of $60 \%$ acetone and $80 \%$ methanol with stirring at $150 \mathrm{rpm}$ for $24 \mathrm{hr}$ at $25^{\circ} \mathrm{C}$ to obtain acetone and methanol extracts. The mixture was filtered through two layers of Whatman no. 1 filter paper. The same quantity of sample was boiled at $100^{\circ} \mathrm{C}$ for $3 \mathrm{hr}$ with $100 \mathrm{~mL}$ deionized distilled water to obtain a hot water extract. The mixture was cooled to room temperature and filtered through Whatman no. 1 filter paper. The residues were then extracted with two additional $100 \mathrm{~mL}$ aliquots of acetone, methanol, and deionized water, as described above. The combined extracts were evaporated with a rotary evaporator (Eyela, Saitama, Japan) at $40^{\circ} \mathrm{C}$, and the remaining solvent was removed with a freeze-drier (Optizen, Daejeon, Korea). The yields from the acetone, methanol, and hot water extracts of $P$. ostreatus were $22.50,13.78$, and $22.16 \%(\mathrm{w} / \mathrm{w})$, respectively.

Antioxidant activity by $\beta$-carotene-linoleic acid. Antioxidant activity was determined by measuring the inhibition of volatile organic compounds and the conjugated diene hydroperoxides arising from linoleic acid oxidation [10]. A stock solution of a $\beta$-carotene-linoleic acid mixture was prepared as follows: $0.5 \mathrm{mg} \beta$-carotene was dissolved in $1 \mathrm{~mL}$ of chloroform, and $25 \mu \mathrm{L}$ of linoleic acid and $200 \mathrm{mg}$ Tween 40 was added. The chloroform was removed completely using a vacuum evaporator. Then, $100 \mathrm{~mL}$ of oxygenated distilled water was added with vigorous shaking; $2.5 \mathrm{~mL}$ of this reaction mixture was dispensed to test tubes, $0.5 \mathrm{~mL}$ of various concentrations $(0.5 \sim 20.0 \mathrm{mg} / \mathrm{mL})$ of the extracts in methanol was added, and the reaction mixture was incubated for up to $2 \mathrm{hr}$ at $50^{\circ} \mathrm{C}$. The same procedure was repeated with the positive controls BHT and TOC, and a blank. After the incubation, the absorbance of the mixtures was measured at 490 $\mathrm{nm}$ using a spectrophotometer (Optizen POP; Mecasys Co. Ltd., Daejeon, Korea). The absorbance was measured until the $\beta$-carotene color disappeared. The $\beta$-carotene bleaching rate (R) was calculated according to Eq. (1).

$$
\mathrm{R}=\ln (\mathrm{a} / \mathrm{b}) / \mathrm{t}
$$

where, $\ln =$ natural $\log , a=$ absorbance at time $t(0)$, and $\mathrm{b}=$ absorbance at time $\mathrm{t}(120 \mathrm{~min})$. The antioxidant activity (AA) was calculated as the percent inhibition relative to the control using Eq. (2).

$$
\mathrm{AA}=\left[\left(\mathrm{R}_{\text {control }}-\mathrm{R}_{\text {sample }}\right) / \mathrm{R}_{\text {control }}\right] \times 100
$$

AAs of the extracts were compared with those of BHT and TOC at $0.5 \mathrm{mg} / \mathrm{mL}$ and with a blank consisting of $0.5 \mathrm{~mL}$ methanol.

Reducing power. Reducing power was determined according to the method of Gulcin et al. [11]. Each extract $(1 \sim 8 \mathrm{mg} / \mathrm{mL})$ in methanol $(2.5 \mathrm{~mL})$ was mixed with $2.5 \mathrm{~mL}$ of $200 \mathrm{mM}$ sodium phosphate buffer $(\mathrm{pH} 6.6)$ and $2.5 \mathrm{~mL}$ of $1 \%$ potassium ferricyanide, and the mixture was incubated at $50^{\circ} \mathrm{C}$ for $20 \mathrm{~min}$. Then, $2.5 \mathrm{~mL}$ of $10 \%$ trichloroacetic acid was added, and the mixture was centrifuged at $200 \times \mathrm{g}$ (6K 15; Sigma, Mannheim, Germany) for $10 \mathrm{~min}$. The upper layer $(2.5 \mathrm{~mL})$ was mixed with $2.5 \mathrm{~mL}$ of deionized water and $0.5 \mathrm{~mL}$ of $0.1 \%$ ferric chloride. Finally, the absorbance was measured at $700 \mathrm{~nm}$ against a blank. BHT and TOC were used as positive controls.

\section{Scavenging effect on 1,1-diphenyl-2-picrylhydrazyl radi-} cals. The hydrogen atom or electron donation ability of the corresponding extracts and some pure compounds were measured from the bleaching of the purple colored DPPH methanol solution [12]. Four $\mathrm{mL}$ of various concentrations $(0.125 \sim 2.0 \mathrm{mg} / \mathrm{mL})$ of the extracts in methanol was added to $1 \mathrm{~mL}$ of DPPH radical solution in methanol (final concentration of DPPH was $0.2 \mathrm{mM}$ ). The mixture was shaken vigorously and allowed to stand for $30 \mathrm{~min}$, and the absorbance of the resulting solution was measured at $517 \mathrm{~nm}$ using a spectrophotometer. Inhibition of the DPPH free radical in percent (I\%) was calculated as:

$$
\mathrm{I} \%=\left[\left(\mathrm{A}_{\text {control }}-\mathrm{A}_{\text {sample }}\right) / \mathrm{A}_{\text {control }}\right] \times 100
$$

where, $\mathrm{A}_{\text {control }}$ is the absorbance of the control reaction (containing all reagents except the test compound), and $\mathrm{A}_{\text {sample }}$ is the absorbance of the test compound. BHT, TOC, and L-ascorbic acid were used as positive controls.

Chelating effects on ferrous ions. The chelating effect was determined according to the method of Dinis et al. [13]. Briefly, $2 \mathrm{~mL}$ of various concentrations $(0.063 \sim 1.0$ 
$\mathrm{mg} / \mathrm{mL}$ ) of the extracts in methanol was added to a solution of $2 \mathrm{mM} \mathrm{FeCl}_{2}(0.05 \mathrm{~mL})$. The reaction was initiated by adding $5 \mathrm{mM}$ ferrozine $(0.2 \mathrm{~mL})$. The total volume was adjusted to $5 \mathrm{~mL}$ with methanol, and the mixture was shaken vigorously and left at room temperature for $10 \mathrm{~min}$. The absorbance of the solution was measured spectrophotometrically at $562 \mathrm{~nm}$. The inhibition percentage of the ferrozine- $\mathrm{Fe}^{2+}$ complex formation was calculated using the following formula:

Metal chelating effect $(\%)$

$$
=\left[\left(\mathrm{A}_{\text {control }}-\mathrm{A}_{\text {sample }}\right) / \mathrm{A}_{\text {control }}\right] \times 100
$$

where, $\mathrm{A}_{\text {control }}$ is the absorbance of the control (control contained $\mathrm{FeCl}_{2}$ and ferrozine; complex formation molecules), and $\mathrm{A}_{\text {sample }}$ is the absorbance of the test compound. BHT and TOC were used as positive controls.

Analysis of phenolic compounds. Fifteen standard phenolic compounds, including gallic acid, pyrogallol, homogentisic acid, protocatechuic acid, (+)-catechin, chlorogenic acid, caffeic acid, vanillin, ferulic acid, naringin, resveratrol, naringenin, hesperetin, formononetin, and biochanin-A were purchased from Sigma Aldrich and used for calibration curves. The standard stock solutions (50, 100,250 , and $500 \mathrm{ppm}$ ) were prepared in DMSO. Sample compounds were identified based on retention times of authentic standards and were quantified by comparing their peak areas with those of the standard curves.

Sample preparation for the phenolic compound analysis followed Kim et al. [14]. Two grams of dried mushroom powder were mixed with $10 \mathrm{~mL}$ of acetonitrile and $2 \mathrm{~mL}$ of $0.1 \mathrm{~N}$ hydrochloric acid and stirred at $150 \mathrm{rpm}$ for $2 \mathrm{hr}$ at room temperature. The suspension was filtered through Whatman no. 42 filter paper. The extract was freeze-dried, and the residues were redissolved in $10 \mathrm{~mL}$ of $80 \%$ aqueous methanol (HPLC grade) and filtered through a $0.45 \mu \mathrm{m}$ nylon membrane filter (Titan, Rockwood, TN, USA). The $20 \mu \mathrm{L}$ filtrate was loaded onto an Agilent-1100 series liquid chromatography HPLC system (Agilent Technologies, Waldbronn, Germany). Separation was achieved on a $250 \mathrm{~nm} \times 4.6 \mathrm{~mm}$ i.d., $5 \mu \mathrm{m}$, YMC-
Pack ODS AM (YMC Co. Ltd., Kyoto, Japan) column. The mobile phase was distilled water with $0.1 \%$ glacial acetic acid (solvent $\mathrm{A}$ ) and acetonitrile with $0.1 \%$ glacial acetic acid (solvent $\mathrm{B}$ ). The gradient was $0 \mathrm{~min}, 92 \% \mathrm{~A}$; 0 2 $\mathrm{min}, 90 \% \mathrm{~A} ; 2 \sim 27 \mathrm{~min}, 70 \% \mathrm{~A} ; 27 \sim 50 \mathrm{~min}, 10 \% \mathrm{~A}$; 50 51 min, 0\% A; 51 60 min, 0\% A; 60 63 min, 92\% A. The run time was $60 \mathrm{~min}$ using a flow rate of $1 \mathrm{~mL} / \mathrm{min}$. Detection was performed with a diode array detector at a wavelength of $280 \mathrm{~nm}$.

Tyrosinase inhibition. Tyrosinase inhibition activity was determined using the modified dopachrome method with L-DOPA as the substrate [15]. A 96-well microtiter plate was used to measure absorbance at $475 \mathrm{~nm}$ with $700 \mathrm{~nm}$ as a reference. Extract fractions were dissolved in $50 \%$ DMSO. Each well contained $40 \mu \mathrm{L}$ of sample with $80 \mu \mathrm{L}$ of phosphate buffer $(0.1 \mathrm{M}, \mathrm{pH} 6.8), 40 \mu \mathrm{L}$ of tyrosinase (31 units $/ \mathrm{mL})$, and $40 \mu \mathrm{L}$ of L-DOPA $(2.5 \mathrm{mM})$. The mixture was incubated for $10 \mathrm{~min}$ at $37^{\circ} \mathrm{C}$, and absorbance was measured at $475 \mathrm{~nm}$ using a UVM 340 microplate reader (Asys, Eugendorf, Austria). Each sample was accompanied by a blank containing all components except L-DOPA. L-ascorbic acid and kojic acid were used as positive controls. The results were compared with a control consisting of $50 \%$ DMSO in place of the sample. The percentage of tyrosinase inhibition was calculated as follows:

$$
\left[\left(\mathrm{A}_{\text {control }}-\mathrm{A}_{\text {sample }}\right) / \mathrm{A}_{\text {control }}\right] \times 100 \%
$$

Statistical analysis. Data are expressed as means \pm SDs of three replicate determinations and were analyzed by SPSS ver. 13 (SPSS Inc., Chicago, IL, USA). A one way analysis of variance and Duncan's new multiple-range test were used to determine the differences among the means.

\section{Results and Discussion}

Aantioxidant activity against $\beta$-carotene-linoleic acid. The acetone, methanol, and hot water extracts of $P$. ostreatus showed different patterns of antioxidant activi-

Table 1. Antioxidant activity against $\beta$-carotene-linoleic acid of different concentrations of various extracts from the fruiting bodies of Pleurotus ostreatus

\begin{tabular}{lccc}
\hline \hline \multirow{2}{*}{$\begin{array}{l}\text { Solvent and } \\
\text { control }\end{array}$} & \multicolumn{3}{c}{ Sample concentration $(\mathrm{mg} / \mathrm{mL})$} \\
\cline { 2 - 4 } & 0.5 & 2.0 & 8.0 \\
\hline Acetone & $68.73 \pm 0.18$ & $89.94 \pm 0.19$ & $91.02 \pm 0.22$ \\
Methanol & $65.89 \pm 0.13$ & $84.25 \pm 0.22$ & $91.12 \pm 0.28$ \\
Hot water & $65.32 \pm 0.22$ & $58.92 \pm 0.35$ & $85.62 \pm 0.17$ \\
BHT & $95.21 \pm 0.17$ & - & - \\
TOC & $96.02 \pm 0.18$ & - & - \\
\hline
\end{tabular}

Values expressed as means \pm SD $(n=3)$.

-, not analyzed; BHT, butylated hydroxytoluene; TOC, $\alpha$-tocopherol. 
Table 2. Reducing power of different concentrations of various extracts from the fruiting bodies of Pleurotus ostreatus

\begin{tabular}{lcccc}
\hline \hline \multirow{2}{*}{$\begin{array}{l}\text { Solvent and } \\
\text { control }\end{array}$} & \multicolumn{4}{c}{ Sample concentration $(\mathrm{mg} / \mathrm{mL})$} \\
\cline { 2 - 5 } & 1.0 & 2.0 & 4.0 & 8.0 \\
\hline Acetone & $0.361 \pm 0.07$ & $0.611 \pm 0.10$ & $0.969 \pm 0.11$ & $1.540 \pm 0.17$ \\
Methanol & $0.541 \pm 0.03$ & $0.712 \pm 0.05$ & $0.996 \pm 0.05$ & $1.252 \pm 0.06$ \\
Hot water & $0.362 \pm 0.07$ & $0.473 \pm 0.11$ & $0.705 \pm 0.15$ & $1.262 \pm 0.23$ \\
BHT & $3.212 \pm 0.49$ & - & - & - \\
TOC & $2.162 \pm 0.32$ & - & - & - \\
\hline
\end{tabular}

Values expressed as means $\pm \mathrm{SD}(\mathrm{n}=3)$.

-, not analyzed; BHT, butylated hydroxytoluene; TOC, $\alpha$-tocopherol.

ties against $\beta$-carotene-linoleic acid. The methanol extract showed the strongest linoleic acid inhibition capacity $(95.06 \%)$ at $20 \mathrm{mg} / \mathrm{mL}$ concentration as compared to the acetone and hot water extracts (Table 1). Comparable antioxidant activity results of volatile solvent extracts from several commercial and medicinal mushrooms have been reported [16]. It is likely that the antioxidative components in the mushroom extracts reduced $\beta$-carotene destruction by neutralizing the linoleate free radical and other free radicals formed.

Reducing power. The reducing power of the $P$. ostreatus acetone, methanol, and hot water extracts as a function of their concentration is shown in Table 2. The reducing power increased with increasing concentration. The strongest reducing power inhibition was identified in the acetone extract at a concentration of $8 \mathrm{mg} / \mathrm{mL}$. A value of 1.54 and the lowest inhibition of reducing power (1.25) was exhibited by the methanol extract. The reducing power values of BHT and TOC at $1.0 \mathrm{mg} / \mathrm{mL}$ were 3.21 and 2.16, respectively (Table 2). Reducing power properties are generally associated with the presence of reductones, which exert antioxidant action by breaking the free radical chain and donating a hydrogen atom $[17,18]$.

Scavenging effect on DPPH. The scavenging effects of the acetone, methanol, and hot water extracts from the fruiting bodies of $P$. ostreatus on DPPH radicals increased with increasing concentration. At $0.125 \sim 2.0 \mathrm{mg} / \mathrm{mL}$, the scavenging abilities of the acetone, methanol, and hot water extracts on the DPPH radical ranged from 33.62 $91.52 \%, 49.33 \sim 85.13 \%$, and $36.35 \sim 82.81 \%$, respectively (Fig. 1). The results indicated that the acetone extract possessed good activity, whereas the methanol and hot water extracts showed moderate and poor activity, respectively, at the concentrations tested. However, at $0.125 \sim 2.0 \mathrm{mg} /$ $\mathrm{mL}$, BHT, TOC, and L-ascorbic acid showed excellent scavenging ability of $85.25 \sim 98.74 \%, 67.37 \sim 97.78 \%$, and 96.74 98.23\%, respectively. Lee et al. [19] reported that the ethanol extracts of Hypsizygus marmoreus, Agaricus bisporus, and P. citrinopileatus fruiting bodies scavenged DPPH radicals by $46.6 \sim 68.4 \%$ at $5 \mathrm{mg} / \mathrm{mL}$. The scaveng-

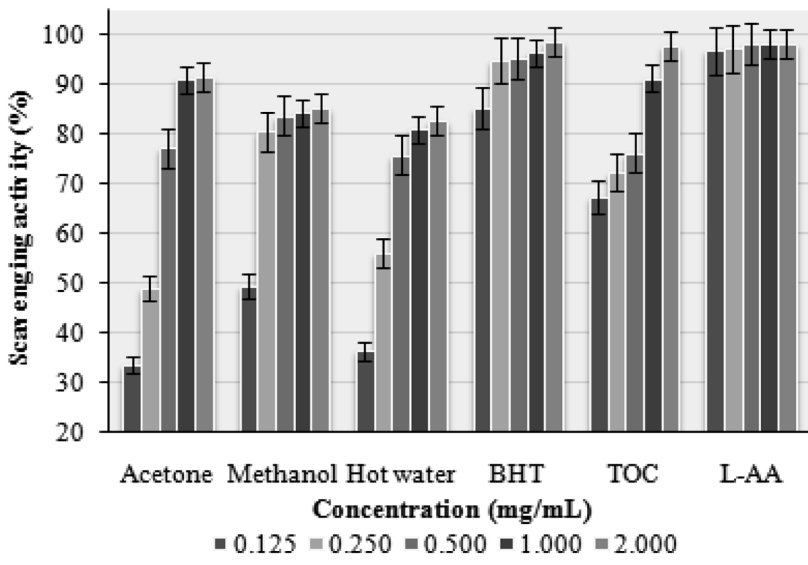

Fig. 1. Scavenging activity of various extracts from the fruiting bodies of Pleurotus ostreatus against 1,1-diphenyl-2picrylhydrazyl. Values expressed as means $\pm \mathrm{SE}(\mathrm{n}=3)$. BHT, butylated hydroxytoluene; TOC, $\alpha$-tocopherol; L-AA, L-ascorbic acid.

ing abilities of the fruiting bodies, mycelia, and filtrate of the cold and hot water extracts at $20 \mathrm{mg} / \mathrm{mL}$ were 20.7 $52.3 \%, 37.6 \sim 48.3 \%$, and $19.6 \sim 23.3 \%$, respectively. It seems that the scavenging ability of $P$. ostreatus fruiting bodies was more effective than those mentioned above. Various extracts might react with free radicals, particularly the peroxy radicals, which are the major propagators of the fat autoxidation chain, thereby terminating the chain reaction [20]. The antioxidant activity of natural antioxidants is due to the termination of the free radical reaction [17].

Chelating effects on ferrous ions. The chelating ability of the acetone, methanol, and hot water extracts at five different concentrations $(0.063,0.125,0.250,0.500$, and $1.000 \mathrm{mg} / \mathrm{mL}$ ) from the P. ostreatus fruiting bodies toward ferrous ions was investigated. BHT and TOC were used as ferrous ion standards. As shown in Fig. 2, the chelating capacity of the extracts increased with increasing concentration. The strongest chelating effect $(85.66 \%)$ was obtained with the acetone extract at $1.0 \mathrm{mg} / \mathrm{mL}$. At this concentration, the lowest chelating effect was exhibited by the hot water extract $(82.29 \%)$. All of the extracts evalu- 


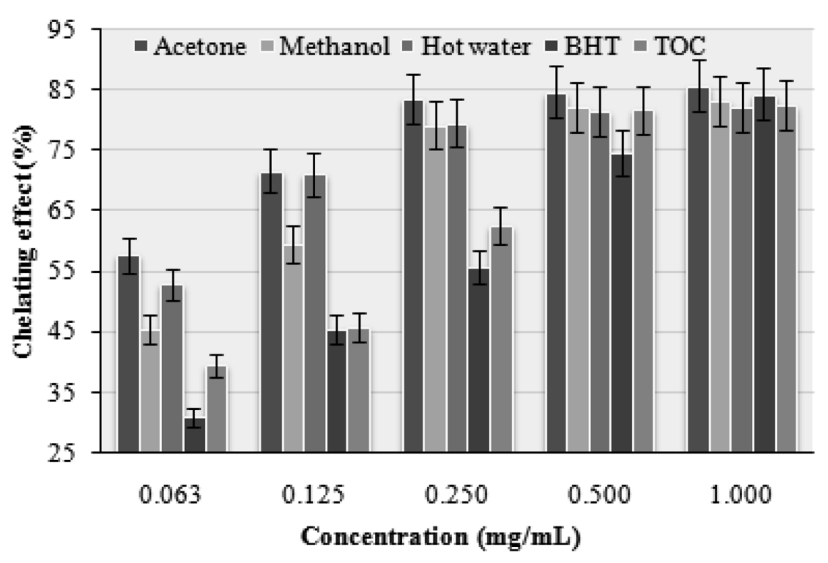

Fig. 2. Chelating effect of various Pleurotus ostreatus extracts. Values expressed as means $\pm \mathrm{SE}(\mathrm{n}=3)$. BHT, butylated hydroxytoluene; TOC, $\alpha$-tocopherol.

ated here showed significantly higher chelating effects on ferrous ions than those of the standards, BHT, or TOC at concentrations of $0.063,0.125,0.250$, and $0.5 \mathrm{mg} / \mathrm{mL}$, respectively. Ganoderma tsugae and Agrocybe cylindracea hot water extracts at $20 \mathrm{mg} / \mathrm{mL}$ chelated ferrous ions by $39.5 \sim 42.6 \%$ and $45.8 \%$, respectively $[21,22]$. At $1 \sim 5$ $\mathrm{mg} / \mathrm{mL}$, the chelating abilities of $H$. marmoreus and P. citrinopileatus were $75.6 \sim 92.6 \%$ [19]. It seems that the chelating ability of $P$. ostreatus on ferrous ions was similar to that of $H$. marmoreus and P. citrinopileatus but more effective than that of $G$. tsugae and A. cylindracea. Chelating agents may serve as secondary antioxidants, because they reduce the redox potential thereby stabilizing the oxidized form of the metal ions. As ferrous ions are the most effective pro-oxidants in food systems [23], the high ferrous-ion chelating ability of the various extracts from the fruiting bodies of $P$. ostreatus could be beneficial.

Analysis of phenolic compounds. Gallic acid, pyrogallol, homogentisic acid, protocatechuic acid, $(+)$ catechin, chlorogenic acid, caffeic acid, vanillin, ferulic acid, naringin, resveratrol, naringenin, hesperetin, formononetin, and biochanin-A were used as standards to detect phenolic compounds in the $P$. ostreatus extracts. Seven phenolic compounds, gallic acid, protocatechuic acid, chlorogenic acid, naringenin, hesperetin, formononetin, and biochanin-A were identified in the P. ostreatus extract (Fig. 3). The total phenolic compound content was $188 \mu \mathrm{g} / \mathrm{g}$. The highest phenolic compound concentration was recorded as protocatechuic acid $(81 \mu \mathrm{g} / \mathrm{g})$, followed by gallic acid $(36 \mu \mathrm{g} /$ g), chlorogenic acid $(27 \mu \mathrm{g} / \mathrm{g})$, formononetin $(14 \mu \mathrm{g} / \mathrm{g})$, naringenin $(10 \mu \mathrm{g} / \mathrm{g})$, hesperetin $(10 \mu \mathrm{g} / \mathrm{g})$, and biochaninA $(10 \mu \mathrm{g} / \mathrm{g})$. Thus, the phenolic compound content could be used as an important indicator of antioxidant capacity. Several reports have convincingly shown a close relationship between antioxidant activity and phenolic content [24]. Mushroom extracts have high levels of phenolic

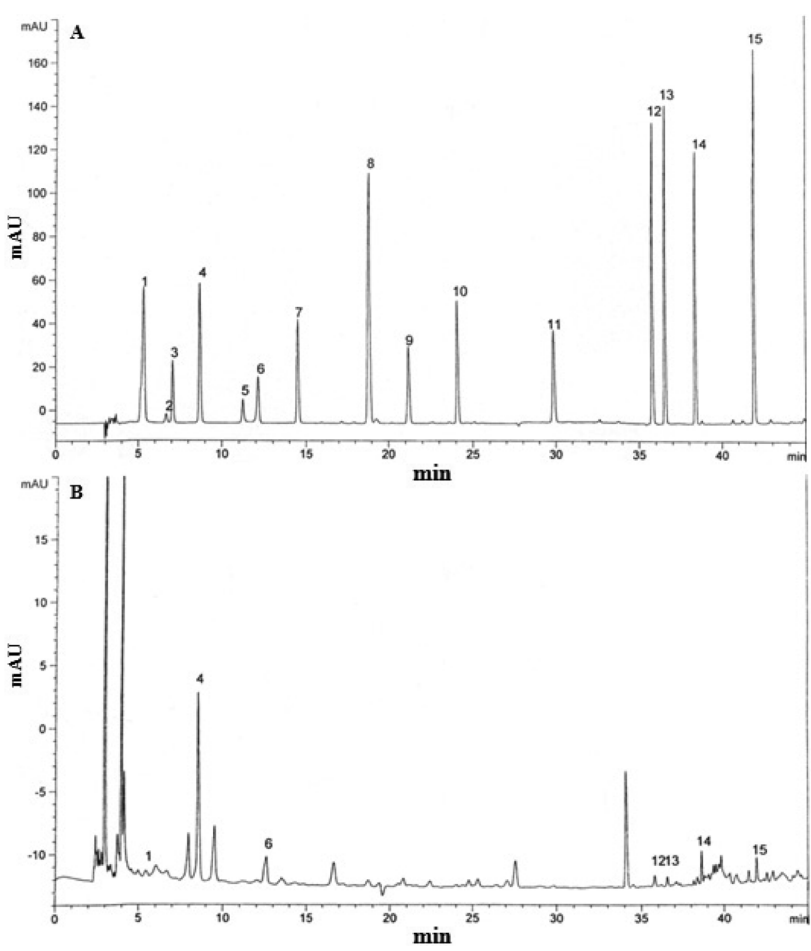

Fig. 3. High performance liquid chromatography of phenolic compounds. A, Standard mixture of 15 phenolic compounds; B, Pleurotus ostreatus extract. 1, gallic acid; 2, pyrogallol; 3, homogentisic acid; 4, protocatechuic acid; $5,(+)$ catechin; 6 , chlorogenic acid; 7 , caffeic acid; 8, vanillin; 9, ferulic acid; 10, naringin; 11, resveratrol; 12, naringenin; 13, hesperetin; 14, formononetin; 15 , biochanin-A.

compounds, which are composed of one or more aromatic rings bearing one or more hydroxyl groups, and exhibit extensive free radical-scavenging activities as hydrogen donors or electron-donating agents, as well as metal ionchelating properties. The greater numbers of hydroxyl groups in the phenolics may result in higher antioxidant activity $[25,26]$.

Tyrosinase inhibition. Tyrosinase inhibitory activities of the acetone, methanol, and hot water extracts from the $P$. ostreatus fruiting bodies increased with increasing concentration. At $0.125 \sim 1.0 \mathrm{mg} / \mathrm{mL}$, the tyrosinase inhibition of the acetone, methanol, and hot water extracts were in the range of $11.37 \sim 52.05 \%, 11.36 \sim 59.56 \%$, and $9.60 \sim 49.60 \%$, respectively (Fig. 4). These results showed that the methanol extract had good tyrosinase inhibitory activity, whereas the acetone and hot water extracts showed moderate and poor activity, respectively, at the concentrations tested. However, at $0.125 \sim 1.0 \mathrm{mg} / \mathrm{mL}$, L-ascorbic acid and kojic acid showed excellent scavenging abilities of 75.12 $92.74 \%$ and $91.23 \sim 99.00 \%$, respectively. The inhibition of tyrosinase activity might depend on the hydroxyl groups on the phenolic compounds of the mushroom extracts, 


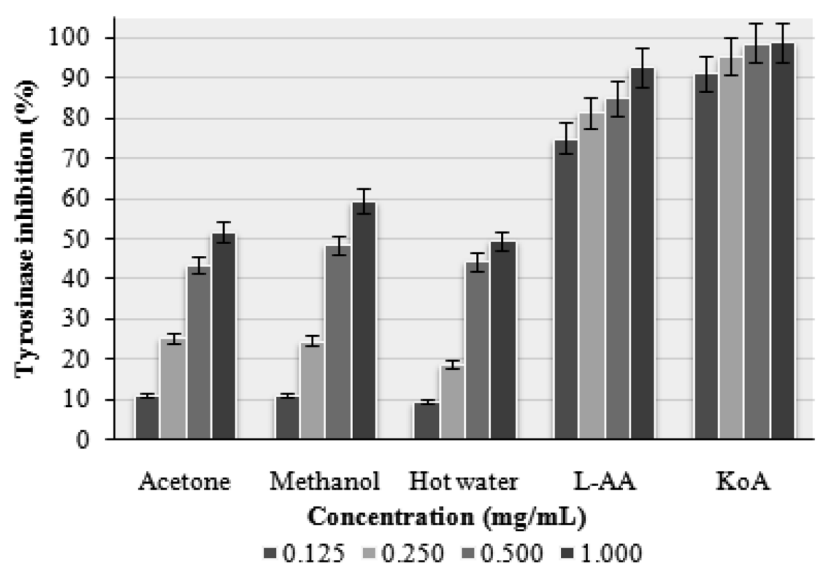

Fig. 4. Tyrosinase inhibition activity of various Pleurotus ostreatus extracts. Values expressed as means $\pm \mathrm{SE}$ $(\mathrm{n}=3)$. L-AA, L-ascorbic acid; KoA, kojic acid.

which may form hydrogen bonds with an enzyme site, leading to lower enzymatic activity. Some tyrosinase inhibitors act through hydroxyl groups that bind to the tyrosinase active site, resulting in steric hindrance or altered conformation $[27,28]$. Gallic acid is an effective tyrosinase activity inhibitor $[29,30]$. The antioxidant activity mechanism may also be an important reason for tyrosinase inhibition activity [28]. Therefore, high level of phenols and good antioxidant and antityrosinase activities indicated that the $P$. ostreatus fruiting bodies could be used as a natural food source of antioxidants.

\section{Acknowledgements}

This research was supported by a mutual research grant from the Rural Development Administration (Agenda 927-63; No. 200901OFT092763229).

\section{References}

1. Pidgeon ER, Anderson RW. Demand trend in Canada's mushroom industry. Can Farm Econ 1981;16:1-6.

2. Alam N, Amin R, Khan A, Ara I, Shim MJ, Lee MW, Lee TS. Nutritional analysis of cultivated mushrooms in Bangladesh: Pleurotus ostreatus, Pleurotus sajor-caju, Pleurotus florida and Calocybe indica. Mycobiology 2008;36:228-32.

3. Alam N, Amin R, Khan A, Ara I, Shim MJ, Lee MW, Lee UY, Lee TS. Comparative effects of oyster mushrooms on lipid profile, liver and kidney function in hypercholesterolemic rats. Mycobiology 2009;37:37-42.

4. Halliwell B, Gutteridge JM. Oxygen toxicity, oxygen radicals, transition metals and disease. Biochem J 1984;219:1-14.

5. Simic MG. Mechanisms of inhibition of free-radical processes in mutagenesis and carcinogenesis. Mutat Res 1988;202:37786.

6. Teissedre PL, Landrault N. Wine phenolics: contribution to dietary intake and bioavailability. Food Res Int 2000;33:4617.
7. Cheung LM, Cheung PC, Ooi VE. Antioxidant activity and total phenolics of edible mushroom extracts. Food Chem 2003;81:249-55.

8. Zawistowski J, Biliaderis CG, Eskin NA. Polyphenol oxidase. In: Robinson DS, Eskin NA, editors. Oxidative enzymes in foods. London: Elsevier; 1991. p. 217-73.

9. Robb DA. Tyrosinase. In: Lontie R, editor. Copper proteins and copper enzymes. Boca Raton: CRC Press; 1984. p. 20740.

10. Dapkevicius A, Venskutonis R, van Beek TA, Linssen JP. Antioxidant activity of extracts obtained by different isolation procedures from some aromatic herbs grown in Lithuania. J Sci Food Agric 1998;77:140-6.

11. Gulcin I, Buyukokuroglu ME, Oktay M, Kufrevioglu OI. Antioxidant and analgesic activities of turpentine of Pinus nigra Arn. subsp. pallsiana (Lamb.) Holmboe. J Ethnopharmacol 2003;86:51-8.

12. Cuendet M, Hostettmann K, Potterat O, Dyatmiko W. Iridoid glucosides with free radical scavenging properties from Fagraea blumei. Helvetica Chimica Acta 1997;80:1144-52.

13. Dinis TC, Maderia VM, Almeida LM. Action of phenolic derivatives (acetaminophen, salicylate, and 5-aminosalicylate) as inhibitors of membrane lipid peroxidation and as peroxyl radical scavengers. Arch Biochem Biophys 1994;315: 161-9.

14. Kim EH, Kim SH, Chung JI, Chi HY, Kim JA, Chung IM. Analysis phenolic compounds and isoflavones in soybean seeds (Glycine max (L.) Merill) and sprouts grown under different conditions. Eur Food Res Technol 2006;222:201-8.

15. Masuda T, Yamashita D, Takeda Y, Yonemori S. Screening for tyrosinase inhibitors among extracts of seashore plants and identification of potent inhibitors from Garcinia subelliptica. Biosci Biotechnol Biochem 2005;69:197-201.

16. Mau JL, Chang CN, Huang SJ, Chen CC. Antioxidant properties of methanolic extracts from Grifola frondosa, Morchella esculenta, and Termitomyces albuminosus mycelia. Food Chem 2004;87:111-8.

17. Shimada K, Fujikawa K, Yahara K, Nakamura T. Antioxidative properties of xanthan on the autoxidation of soybean oil in cyclodextrin emulsion. J Agric Food Chem 1992;40:945-8.

18. Barros L, Ferreira MJ, Queiros B, Ferreira IC, Baptista P. Total phenols, ascorbic acid, $\beta$-carotene and lycopene in Portuguese wild edible mushrooms and their antioxidant activities. Food Chem 2007;103:413-9.

19. Lee YL, Huang GW, Liang ZC, Mau JL. Antioxidant properties of three extracts from Pleurotus citrinopileatus. LWTFood Sci Technol 2007;40:823-33.

20. Shahidi F, Wanasundara PK. Phenolic antioxidants. Crit Rev Food Sci Nutr 1992;32:67-103.

21. Mau JL, Tsai SY, Tseng YH, Huang SJ. Antioxidant properties of hot water extracts from Ganoderma tsugae Murrill. LWT-Food Sci Technol 2005;38:589-97.

22. Tsai SY, Huang SJ, Mau JL. Antioxidant properties of hot water extracts from Agrocybe cylindracea. Food Chem 2006;98:670-7.

23. Yamauchi R, Tatsumi Y, Asano M, Kato K, Ueno Y. Effect of metal salts and fructose on the autoxidation of methyl linoleate in emulsions. Agric Biol Chem 1988;52:849-50.

24. Duan X, Wu G, Jiang Y. Evaluation of the antioxidant properties of litchi fruit phenolics in relation to pericarp browning prevention. Molecules 2007;12:759-71. 
25. Prasad KN, Divakar S, Shivamurthy GR, Aradhya SM. Isolation of a free radical scavenging antioxidant from water spinach (Ipomoea aquatica Forsk). J Sci Food Agric 2005;85: 1461-8.

26. Rangkadilok N, Sitthimonchai S, Worasuttayangkurn L, Mahidol C, Ruchirawat M, Satayavivad J. Evaluation of free radical scavenging and antityrosinase activities of standardized longan fruit extract. Food Chem Toxicol 2007;45:32836.

27. Baek HS, Rho HS, Yoo JW, Ahn SM, Lee JY, Lee J, Kim MK, Kim DH, Chang IS. The inhibitory effect of new hydroxamic acid derivatives on melanogenesis. Bull Korean
Chem Soc 2008;29:43-6.

28. Kim YJ, Kang KS, Yokozawa T. The anti-melanogenic effect of pycnogenol by its anti-oxidative actions. Food Chem Toxicol 2008;46:2466-71.

29. Kubo I, Chen QX, Nihei KI. Molecular design of antibrowning agents: antioxidative tyrosinase inhibitors. Food Chem 2003;81:241-7.

30. Momtaz S, Mapunya BM, Houghton PJ, Edgerly C, Hussein A, Naidoo S, Lall N. Tyrosinase inhibition by extracts and constituents of Sideroxylon inerme L. stem bark, used in South Africa for skin lightening. J Ethnopharmacol 2008;119: 507-12. 